\title{
Gender Transformative Practices in Early Grade Reading Classrooms
}

\author{
Bhagwan Aryal \\ Assistant Professor, TU
}

\begin{abstract}
This article is based on a research work of 2017 conducted for Plan International Nepal. The research was originally done to assess the reading comprehension of Nepali subject together with basic skills of Mathematics of early graders in grades Two and Three. It focused on assessing existing situation of the early graders'learning status together with early learning environments in relation to early grade reading. It included field work in 17 schools of Four districts, namely, Morang, Makwanpur, Sindhuli and Banke. It aimed to assess the gender transformative practices in selected classrooms of early grades.
\end{abstract}

Keywords: Gender transformative, inclusion, literacy, reading, comprehension, fluency, etc.

\section{Introduction}

Basic literacy is foundation of all kinds of learning. Moreover, ability to read and extract meaning from text is considered to be a fundamental goal of literacy. Reading in fact is a complex cognitive act. According to Snow, Burns and Griffin (1998), reading involves multiple cognitive, emotional, and social abilities, each of which impacts the beginning reader's success. Early grade reading habit of children lays the foundation of their later development. To highlight this, Gove and Cvelich (2010) state that children who fail to learn to read in the first few grades of school are handicapped in later grades as they must absorb increasing amounts of instructional content in print form.

RTI International (2009) indicates that learning to read both early and at a sufficient rate is essential for learning to read well which becomes more difficult for the students when they grow older. Children who do not learn to read in the first few grades are more likely to repeat grades and eventually drop out. And the gap between early readers and non-readers increases over time. Nepal School Sector Reform Plan (SSRP, 2009-2015) had set the purpose of providing basic education to ensure children's entry into school at the age of six with basic reading skills in order to continue their stay in schools by valuing their personal worth and meaningful participation. SSRP further intended to improve the quality of learning with the support of physical and instructional facilities, competent and qualified teachers, relevant curricula, textbooks and assessment system and result based management system.

The purpose of reading is comprehension. Understanding the concepts read or heard is comprehension (Gove \& Cvelich, 2010). Reading comprehension is a 
constructive process and that meaning is as dependent on the reader as it is on the text. Comprehension should be developed from the very start among learners. Discussion around early grade reading in Nepal has raised issue of language of instruction among others, as in many countries, laying more emphasis on language teaching rather than building reading competency as specific skill area. Ministry of Education (MoE) has prepared National Early Grade Reading Strategy 2015 to 2020 and has invited all International/Non-government organizations (I/NGOs) and development partners to support in the implementation of the strategy.

The context of gender transformation and inclusion is still an issue in Nepalese education. UNESCO (n.d.) defines inclusion as a process of addressing and responding to the diversity of needs of all learners through increasing participation in learning, cultures and communities, and reducing exclusion within and from education. However, female children in general are excluded from many opportunities in Nepal. Even when from the perspective of gender equality and gender justice is viewed, most textbooks are not able to incorporate aspects that would help children think differently in terms of gender roles/responsibilities, images, power relation, etc. They were still unconsciously reinforcing gender stereotypes (Aryal, Yadava, Maharjan, Adhikari, Acharya, Khatiwada...Gupta, 2014). This article has tried to find out the treatment to male and female child in early grade reading classroom classrooms.

According to Maharjan, Acharya, Khanal and Aryal (2017), Plan International Nepal has been developing model classrooms with wall books, reading corners, charts, word picture, etc. for early grade reading in 208 schools of six working districts, namely, Morang, Sunsari, Sindhuli, Rautahat, Makwanpur and Banke. It had earlier implemented this program in Dolpa too. It provided fund to carry on a research on 'classroom based early grade reading status.' This article focuses on some of the findings of the research related to gender transformative practices in early grades.

An attempt was made to understand gender transformative practices in selected schools and students' households. FGDs with teachers and parents were the method used to get information related to gender transformative practices. The practices as informed by the teachers and parents were correlated with the scores that students particularly girls achieved in reading comprehension and fluency tests.

\section{Objective}

This study aimed to assess reading ability of Grade 2-3 students in view of the Government of Nepal's ongoing National Early Grade Reading Program (NEGRP) 
that focuses primarily on improving the reading skills of students in early grades, especially in grades 1-3 of primary level (Maharjan, Acharya, Khanal \& Aryal, 2017). However, the objective of this study being based on the research was to find out the gender transformative practices in early grades in the sampled districts.

\section{Methodology}

The original research employed a mixed research design. Both quantitative and quantitative data were collected. Since the major purpose was to asses children's reading and comprehension and Mathematics skills quantitative data outweighed the qualitative one. An integrated test was developed in Nepali and Mathematics subjects for Grade 2 and Grade 3 students to assess their Nepali reading ability and basic mathematics comprehension. It also included a reading passage for identifying their fluency.

A total of 427 students from 4 districts - Banke, Makwanpur, Morang and Sindhuli were included in the study. The tests were done in the 17 public schools, of which eight schools were Plan supported and nine schools were without plan's support in EGR. More than fifty percent of the participants of the tests were girl students $(54.56 \%)$. Moreover, an observation checklist was used to collect information about the physical aspects of the classroom and availability of reading materials. Total 16 FGDs were conducted with parents and teachers to collect relevant qualitative data of this study.

\section{Findings and discussion}

In Nepal generally gender disparity in achievement and classroom practices is not prominent in lower grades. Usually gender disparity and gender insensitive practices are observed in upper grades (Maharjan, Acharya, Khanal \& Aryal, 2017). This trend was observed in the current study as well. For example most girls scored slightly higher than their male counterparts in both grades and both types of schools. However in reading fluency, boys significantly did better than their female counterparts, particularly in Plan International Nepal supported schools.

The disparity between writing test score and fluency indicated that the girls' inhibition to speak in front of a stranger affected their fluency test result. Due to gender norms and girls restricted mobility from childhood they take more time than boys to speak out in an unfamiliar setting. In one of the sample schools in Banke during consultant's visit for FGD, a grade teacher informed that a girl peed where she was sitting when Plan International Nepal staff entered the classroom to conduct reading and comprehension tests. According to the teacher the girl was very nervous. 
Table 1: Students' attendance by grade and sex

\begin{tabular}{|c|c|c|c|}
\hline & & \multicolumn{2}{|c|}{ Students' attendance } \\
\hline & & $\begin{array}{c}\text { Plan supported school } \\
\text { Total number of days present in } \\
\text { school }\end{array}$ & $\begin{array}{c}\text { Non-supported } \\
\text { school }\end{array}$ \\
\hline & \multicolumn{3}{|c|}{ Total number days present in school } \\
\hline Grade & Sex of student & Mean & Mean \\
\hline & Boys & 49.29 & 46.93 \\
\hline \multirow[t]{3}{*}{ Two } & Girls & 51.48 & 48.57 \\
\hline & Total & 50.56 & 47.86 \\
\hline & Boys & 52.07 & 44.02 \\
\hline \multirow[t]{2}{*}{ Three } & Girls & 51.17 & 44.29 \\
\hline & Total & 51.61 & 44.16 \\
\hline
\end{tabular}

*Average school opening days: 67 days (Range: 56 to 77 days)

The attendance figure (Table 1) revealed that girls from both grades and types of schools were more regular than boys except in grade Three of Plan supported schools. The average attendance of girls and boys was 49.10 and 48.25 respectively. Average attendance of grade three of supported schools in particular showed boys' attendance insignificantly higher. Parents in FGD also informed that their daughters were more studious than their boys. Likewise teachers complained about boys bunking schools but not girls. They also informed that during religious events/occasions and when they visited their maternal families both boys and girls missed schools for extended period of time.

Discussions with parents of second and third graders revealed that their daughters were more involved in household chores. They said that boys were more involved in play and/or outdoor activities. Discussions with teachers from both types of schools revealed that they had not applied any specific measures to empower girls and intercept the culture of gender discrimination. They used the conventional measures such as walking to everybody's seat and asking what and how they were doing, to reach all the students. There was no systematic intervention to enable teachers and girls themselves to identify and deal with gender issues and thereby empower girls. 
Table 2: Number of students taking private tuition in Nepali

\begin{tabular}{|c|c|c|c|}
\hline \multirow[b]{2}{*}{ Grade } & \multirow[b]{2}{*}{ Sex of student } & \multicolumn{2}{|c|}{ Number of students taking private tuition in Nepali } \\
\hline & & $\begin{array}{c}\text { Plan supported school } \\
\text { Number of students }\end{array}$ & $\begin{array}{c}\text { Non-supported school } \\
\text { Number of students }\end{array}$ \\
\hline \multirow{3}{*}{ Two } & Boys & 6 & 13 \\
\hline & Girls & 7 & 4 \\
\hline & Total & 13 & 17 \\
\hline \multirow{3}{*}{ Three } & Boys & 18 & 6 \\
\hline & Girls & 13 & 2 \\
\hline & Total & 31 & 8 \\
\hline \multicolumn{4}{|c|}{$\begin{array}{l}\text { The tuition taking trend (Table } 2 \text { and Table 3) also indicate that the gender biasnes } \\
\text { existed in almost all clusters of the selected schools. In total there were very fev } \\
\text { students who were taking private tuition. Moreover, number of children taking privat } \\
\text { tuition in Nepali was higher than those in Mathematics. However among those why } \\
\text { were taking private tuition boys outnumbered girls. The parents justified their practice } \\
\text { Table 3: Number of students taking private tuition in Mathematics }\end{array}$} \\
\hline \multicolumn{4}{|c|}{ Number of students taking private tuition in Mathematics } \\
\hline \multirow[t]{2}{*}{ Grade } & Sex of student & $\begin{array}{l}\text { Plan supported school } \\
\text { Number of students }\end{array}$ & $\begin{array}{l}\text { Non-supported school } \\
\text { Number of students }\end{array}$ \\
\hline & Boys & 6 & 8 \\
\hline \multirow[t]{2}{*}{ Two } & Girls & 7 & 4 \\
\hline & Total & 13 & 12 \\
\hline \multirow{3}{*}{ Three } & Boys & 18 & 9 \\
\hline & Girls & 9 & 0 \\
\hline & Total & 27 & 9 \\
\hline
\end{tabular}

For example parents from Makwanpur said that their sons were provided with private tuition not because they discriminated girls but because their boys had poor results in exams. The above deliberations indicated that intervention to ensure gender equity and equality at both school and household levels are yet to be implemented.

\section{Conclusion}

Girls from both grades and types of schools were more regular than boys except in grade three of non-supported schools. In reading fluency test, boys significantly did better than girls, particularly in Plan supported schools. The disparity between writing test score and fluency indicated that the girls' inhibition to speak in front of a stranger affected their fluency test result. Girls' household responsibilities were still greater than that of boys. This practice further augment as the girls get older affecting their studies in higher grades when more time and support in study are required. 
Both types of schools revealed that they had not applied any specific measures to empower girls and intercept the culture of gender discrimination both at school and home. There was no systematic intervention to enable teachers and girls themselves to identify and deal with gender issues and thereby empower girls. Among those who were taking private tuition boys outnumbered girls.

\section{Recommendations}

Often girls gradually fall behind in studies as they grow older. Moreover there are usually gaps between school's practices and expectations and household's practices and expectations from girls. This however does not mean that schools are gender friendly. Therefore key strategies to ensure gender equity and equality should be as follows:

- Gender sensitivity and needs analysis in classroom and school practices should be done.

- Support and interventions on the basis of gender sensitivity and needs analysis to prevent girls from falling back in their studies should be done.

- Strategies such as interactions and critical discussions with girls and boys about sexual division of labor; priorities and aspirations of boys and girls and their families; and sharing of works should be carried to empower and enable both girls and boys to ensure gender justice both at school and household. Periodic thematic consultations with parents to bridging schools and families should also be done.

- Make schools ensure that one of the agendas of teacher parent meeting is gender issue and early grade reading skill.

\section{References}

Aryal, P.N., Yadava, Y.P., Maharjan, R.K., Adhikari, H.R., Acharya, S., Khatiwada, K., Aryal B., \& Gupta, S.P. (2014). Nepal early grade reading materials assessment. Unpublished report submitted to USAID Nepal.

Gove, A., \& Cvelich, P. (2010). Early reading: Igniting education for all. A report by the early grade learning community of practice. NC: Research Triangle Institute (RTI).

Maharjan, R.K., Acharya, S., Khanal, P., \& Aryal, B. (2017). Classroom based early grade reading status. Unpublished report submitted to Plan International Nepal.

Research Triangle Institute (RTI) International (2009). Early Grade Reading Assessment Toolkit. New York: USAID. www.rti.org/brochures/eddata_ii_egra_lac.pdf

Snow, C.E., Burns, M.S., \& Griffin, P. (Eds.). (1998). Preventing reading difficulties in young children. Washington, DC: National Academy Press.

UNESCO. (n.d.). Barriers to inclusive education. http://www.unescobkk. org/education/inclusive-education/what-is-inclusive-education/barriers-to-inclusiveeducation/ 